\title{
Sorption of Barium on Kaolinite, Montmorillonite and Chlorite*
}

\author{
Cahit Eylem \\ Department of Chemistry, Bilkent University and Middle East Technical University, Ankara, Turkey \\ Hasan N. Erten \\ Department of Chemistry, Bilkent University, Ankara, Turkey \\ Hale Göktürk \\ Department of Chemistry, Middle East Technical University, Ankara, Turkey
}

\begin{abstract}
The sorption characteristics of the $\mathrm{Ba}^{2+}$ ion on kaolinite, montmorillonite and chlorite type clays were studied using the batch method. Barium -133 was used as a tracer. The $\mathrm{Ba}^{2+}$ ion concentrations ranged from $10^{-8}$ to $10^{-5}$ mol I-1; synthetic groundwater was used and the grain size of all the solid particles was $<40 \mu \mathrm{m}$. About 6 , 8 and $12 \mathrm{~d}$ of shaking were necessary to reach equilibrium for chlorite, kaolinite and montmorillonite, respectively. The sorption isotherms were described best by Freundlich and Dubinin - Radushkevich type isotherms. Sorption was predominantly reversible for kaolinite and partly reversible for montmorillonite and chlorite.
\end{abstract}

Keywords: Sorption - desorption; clays; batch method; barium; isotherms

\begin{abstract}
The sorption characteristics of $\mathrm{Cs}^{+}$and $\mathrm{Sr}^{2+}$ ions have been studied in this laboratory and the results published recently.1,2 The sorption characteristics of several radiocontaminant nuclides on various clays have been the subject of many recent studies. ${ }^{3-6}$ In this work the sorption behaviour of $\mathrm{Ba}^{2+}$ was studied. No extensive investigations into the sorption of the $\mathrm{Ba}^{2+}$ ion have been reported in the literature to date. The fission product ${ }^{140} \mathrm{Ba}\left(t_{\frac{1}{2}}=12.79 \mathrm{~d}\right)$ is a serious radiocontaminant during the first $100 \mathrm{~d}$ after fission products are discharged into the environment from sources such as nuclear power plants, either routinely or accidentally, and nuclear weapons testing. Another reason for studying the sorption of $\mathrm{Ba}^{2+}$ is related to its chemical properties, which lie between those of $\mathrm{Sr}^{2+}$ and $\mathrm{Ra}^{2+}$, both very important nuclides in the handling of radioactive waste. By comparing the results obtained with those for the sorption of $\mathrm{Sr}^{2+}$, a general trend for alkaline earth metal ions can be obtained.
\end{abstract}

\section{Experimental}

Clay minerals from three regions of Turkey (Sindirgi, Giresun and Afyon) were used in the sorption studies. The clay samples were identified as kaolinite, montmorillonite and chlorite types, respectively, by infrared and X-ray diffraction analysis. Wet sieving followed by sedimentation was used to separate the clay minerals into various sized fractions. The sorption experiments were carried out using synthetic groundwaters with compositions similar to those of groundwaters found in the three regions mentioned above. Table 1 gives the composition of the synthetic groundwaters used.

Barium-133 ( $t_{\frac{1}{2}}=10.7$ years) was used as a tracer in the sorption studies and was obtained from Amersham International (Amersham, Buckinghamshire, UK). The $\mathrm{Ba}^{2+}$ ion concentrations used ranged from $10^{-8}$ to $10^{-5} \mathrm{~mol} 1^{-1}$.

The sorption experiments were carried out using the batch method. Weighed amounts of clay samples were kept in contact with known volumes of water for various times. The samples were shaken at room temperature using a circular type shaker at a speed of $190 \mathrm{rev} \mathrm{min}^{-1}$. To ensure thorough mixing, a volume to mass ratio of $80 \mathrm{ml} \mathrm{g}^{-1}$ was chosen and was kept constant for all samples.

${ }^{*}$ Presented at the 2nd International Conference on Nuclear and Radiochemistry, Brighton, UK, 11-15 July, 1988.
The two phases were separated by centrifuging at 12000 rev $\min ^{-1}$ and the change in the $\mathrm{Ba}^{2+}$ ion concentration in the liquid phase was determined radiochemically using an $\mathrm{NaI}(\mathrm{Tl})$ detector. The distribution ratio, $R_{\mathrm{D}}$, was calculated from the activity measurements before and after sorption as described previously..$^{1,2}$

\section{Results and Discussion}

The particle size distribution in the three types of clay minerals is given in Fig. 1, from which it can be seen that kaolinite has the highest fraction of smaller size particles.

The results of sorption kinetics are illustrated in Fig. 2 for chlorite; it is apparent that saturation is reached in about $6 \mathrm{~d}$. The effect of not shaking the samples appears to be to increase the time required to reach saturation considerably. No significant abrasion effect was observed that reflected itself as higher $R_{\mathrm{D}}$ values for samples that were shaken during sorption studies. Similar results were obtained for kaolinite and montmorillonite type clays, the saturation times being 8 and $12 \mathrm{~d}$, respectively. The sorption rate was found to be highest for chlorite and lowest for montmorillonite. Three different first-order rate constants could be obtained for montmorillonite and two each for chlorite and kaolinite from examina-

Table 1. Chemical composition of synthetic groundwater samples used in the sorption studies

\begin{tabular}{|c|c|c|c|c|c|}
\hline \multirow{2}{*}{\multicolumn{2}{|c|}{$\begin{array}{l}\text { Component/ } \\
\text { mequiv. } 1^{-1}\end{array}$}} & & \multicolumn{3}{|c|}{$\begin{array}{c}\text { Synthetic groundwater } \\
\text { sample }\end{array}$} \\
\hline & & & Sindirgi & Giresun & Afyon \\
\hline $\mathrm{Na}^{+} \ldots$ & . & . & $0.89^{*}$ & 0.22 & 2.08 \\
\hline $\mathrm{K}^{+} \quad \ldots$ & . & . & - & 0.01 & 0.40 \\
\hline $\mathrm{Ca}^{2+} \ldots$ & $\ldots$ & . & 4.70 & 2.28 & 5.46 \\
\hline $\mathrm{Mg}^{2+}$ & . & . . & 3.15 & 0.30 & 3.38 \\
\hline $\mathrm{CO}_{3}^{2-\dagger}$ & .. & $\therefore$ & 0.17 & 0.28 & 0.90 \\
\hline $\mathrm{NO}_{3}^{-}$ & . & .. & 3.14 & 1.34 & 4.48 \\
\hline $\mathrm{Cl}^{-}$ & . & . & 0.84 & 0.02 & 0.25 \\
\hline $\mathrm{SO}_{4}^{2-\dagger}$ & . & . & 0.18 & 0.10 & 0.82 \\
\hline $\mathrm{pH}$ & . & . & 7.2 & 6.5 & 7.1 \\
\hline
\end{tabular}


tion of the solution activity versus time graphs. These results suggest that there are three different sorption sites and/or mechanisms for montmorillonite and two for chlorite and kaolinite.

The sorption rate was observed to decrease by about a factor of two in all instances, if the samples were not shaken during the kinetic studies. The desorption kinetic studies indicate that there is considerable, rapid initial desorption followed by re-adsorption until saturation is reached. The sorption of $\mathrm{Ba}^{2+}$ on kaolinite was observed to be reversible, whereas the sorption on montmorillonite and chlorite was only partly reversible.

The variation in the distribution ratio, $R_{\mathrm{D}}$, as a function of cation loading for the sorption of $\mathrm{Cs}^{+}, \mathrm{Sr}^{2+}$ and $\mathrm{Ba}^{2+}$ ions on kaolinite, montmorillonite and chlorite is shown in Figs. 3 and 4. The relative standard deviation of the $R_{\mathrm{D}}$ values was less than $10 \%$ for all measurements. Typical inverse S-shaped curves are observed in all instances except for the sorption of $\mathrm{Sr}^{2+}$ on kaolinite. The region of greatest change in the values

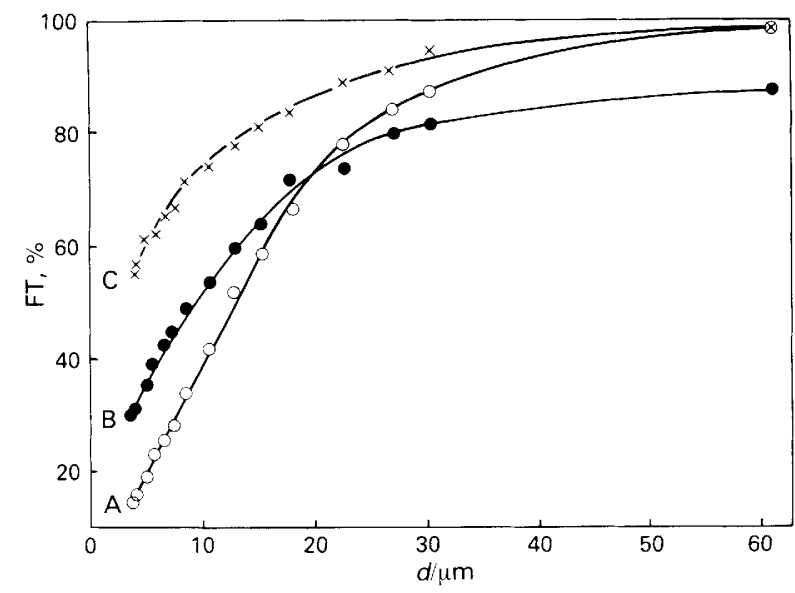

Fig. 1. Size distribution of clay samples. Per cent. finer than (FT) versus diameter of particles (d). (A) Chlorite; (B) montmorillonite; and $(\mathrm{C})$ kaolinite

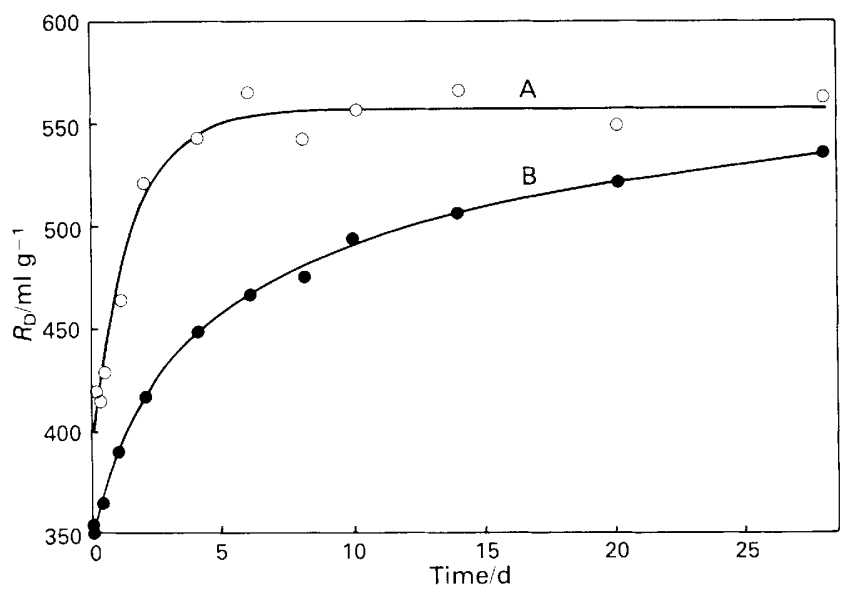

Fig. 2. Sorption kinetics. Change in $R_{\mathrm{D}}$ with contact time for chlorite. Initial $\mathrm{Ba}^{2+}$ concentration $=1.56 \times 10^{-8}$ mequiv. $\mathrm{ml}^{-1}$; particle size $<38 \mu \mathrm{m}$. (A) Shaking speed $190 \mathrm{rev} \mathrm{min}^{-1}$; and (B) no shaking of $R_{\mathrm{D}}$ is very pronounced only for $\mathrm{Cs}^{+}$sorption. The curves suggest that two types of sorption mechanisms are involved, the first taking place at high cation loadings and the second at low cation loadings. The isotherms for the sorption of the $\mathrm{Ba}^{2+}$ ion on kaolinite, montmorillonite and chlorite are shown in Fig. 5 in the form of $\log -\log$ plots. The isotherms are linear for all three types of clay, but with a fairly pronounced deviation from linearity for chlorite.

The experimental data were fitted to three different types of isotherm model, ${ }^{7}$ namely Langmuir, Freundlich and Dubinin Radushkevich isotherms. The best fits were obtained with the Freundlich and Dubinin- Radushkevich type isotherms. The distribution ratio, $R_{\mathrm{D}}$, can be calculated from the Freundlich model using the relationship

$$
R_{\mathrm{D}}=K\left[\mathrm{Ba}^{2+}\right]^{N-1}
$$

where $K$ and $N$ are constants and $\left[\mathrm{Ba}^{2+}\right]$ is the concentration of $\mathrm{Ba}^{2+}$ ion in the solution after sorption $\left(\mathrm{moll}^{-1}\right)$. The values of $K$ and $N$ for the three different clay types are given in Table 2. Similarly, $R_{\mathrm{D}}$ can be calculated from the Dubinin Radushkevich model from the relationship

$$
R_{\mathrm{D}}=\left[\mathrm{Ba}^{2+}\right]^{-1} K_{\mathrm{CEC}} \exp \left\{-K\left[R T \ln \left(1+\left[\mathrm{Ba}^{2+}\right]^{-1}\right)^{2}\right]\right\}
$$

where $K_{\mathrm{CEC}}$ is the cation-exchange capacity per unit mass, $R$ the gas constant, $T$ the temperature $(\mathrm{K})$ and $K$ is a constant.
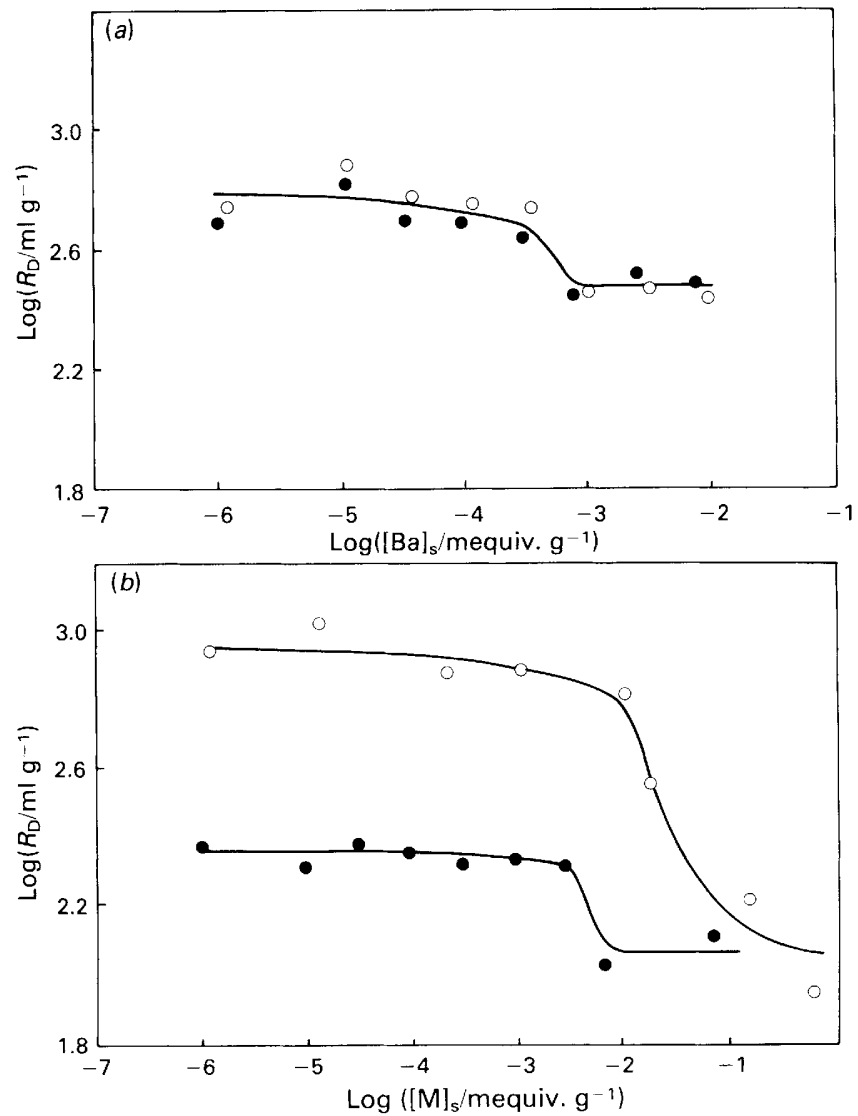

Fig. 3. (a) Sorption/desorption of $\mathrm{Ba}^{2+}$ on chlorite. Particle size $<38$ $\mu \mathrm{m} .(\mathrm{O})$ Sorption; and (a) desorption. (b) Sorption of $\mathrm{Sr}^{2+}$ on montmorillonite. (O) $\mathrm{Sr}^{2+}$ (particle size $<10 \mu \mathrm{m}$ ); and $(\mathbf{O}) \mathrm{Ba}^{2+}$ (particle size $<5 \mu \mathrm{m}$ ). Subscript s refers to solid

Table 2. Empirical parameters obtained from isotherm models

\begin{tabular}{ccccccc}
\multicolumn{3}{r}{ Isotherm model } & & & Parameter \\
Freundlich & $\ldots$ & $\ldots$ & $\ldots$ & $\ldots$ & $\ldots$ & $K$ \\
& & & & & $N$ \\
Dubinin - Radushkevich & $\ldots$ & $\ldots$ & $\ldots$ & $K_{\text {CEC }}$
\end{tabular}

Kaolinite
7.5
0.84
0.054
$6.7 \times 10^{-5}$

Montmorillonite
86.0
0.94
0.22
$6.0 \times 10^{-5}$

Chlorite 


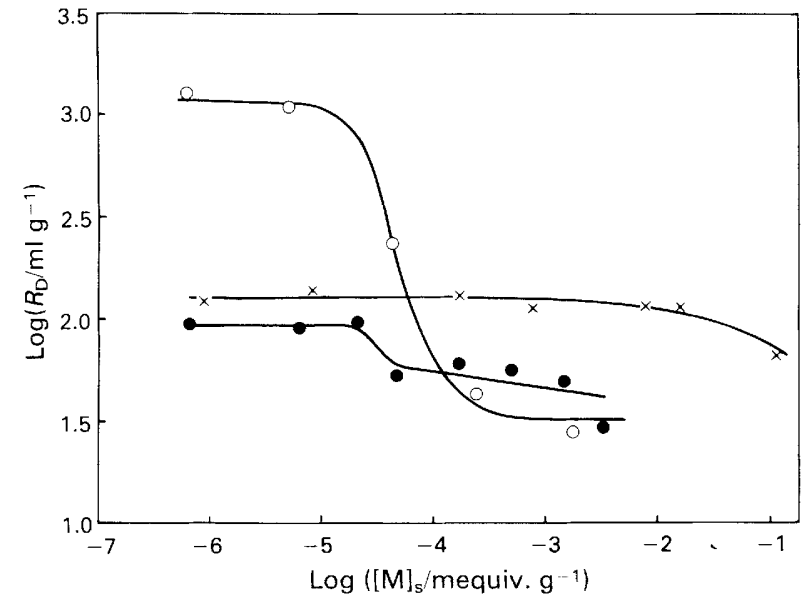

Fig. 4. Sorption of $\mathrm{Cs}^{+}, \mathrm{Sr}^{2+}$ and $\mathrm{Ba}^{2+}$ on kaolinite. (O) $\mathrm{Cs}^{+}$ (particle size $<10 \mu \mathrm{m}) ;(\times) \mathrm{Sr}^{2+}$ (particle size $\left.<10 \mu \mathrm{m}\right)$; and $\left(\mathbf{O} \mathrm{Ba}^{2+}\right.$ (particle size $<5 \mu \mathrm{m})$. Subscript $s$ refers to solid

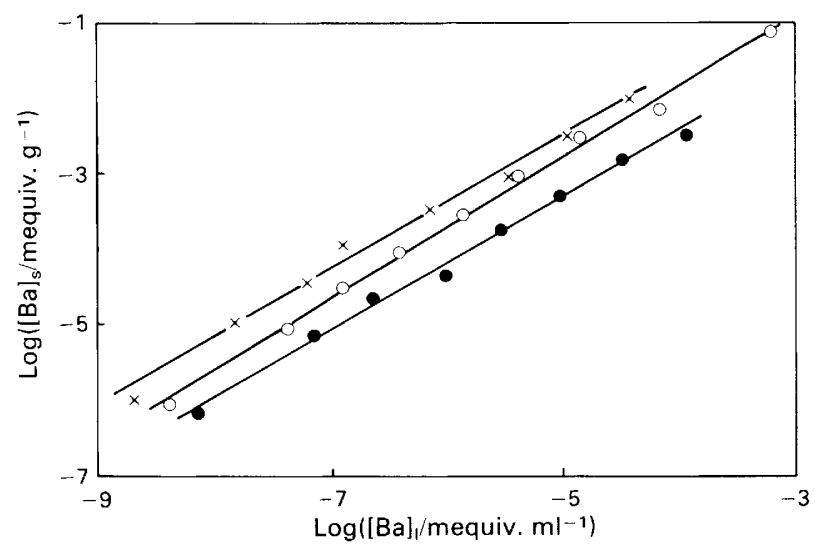

Fig. 5. Sorption isotherms of $\mathrm{Ba}^{2+}$ for the three clay types. Kaolinite (particle size $<5 \mu \mathrm{m}$ ); ( $\bigcirc)$ montmorillonite (particle size $<5$ $\mu \mathrm{m})$; and $(\times)$ chlorite (particle size $<38 \mu \mathrm{m}$ ). Subscript 1 refers to liquid

The values of $K_{\mathrm{CEC}}$ and $K$ for the three types of clay studied are given in Table 2 .

The steady-state values of $R_{\mathrm{D}}$ for the sorption of $\mathrm{Cs}^{+}, \mathrm{Sr}^{2+}$ and $\mathrm{Ba}^{2+}$ and the cation-exchange capacities (CEC) of the different types of clay are given in Table 3 . It can be seen that, generally, the magnitude of $R_{\mathrm{D}}$ is proportional to the CEC. The monovalent alkali metal ion $\mathrm{Cs}^{+}$is sorbed more strongly than the divalent alkaline earth metal cations $\mathrm{Sr}^{2+}$ and $\mathrm{Ba}^{2+}$. Of the three clay types studied, chlorite is the most effective sorbent for the $\mathrm{Ba}^{2+}$ ion. Although chlorite has a lower CEC than montmorillonite, the structural characteristics of these clays may be responsible for the observed $R_{\mathrm{D}}$ values.

The sorption selectivity of various cations on clay minerals appears to depend on both the properties of the cations and the sorbent surface. Cations with higher surface charge densities would be expected to be more effective displacers of bound cations. On the other hand, the hydration of cations is also directly proportional to the charge densities on them. Strongly hydrated cations are bound less strongly on clay mineral surfaces, an effect that acts in the opposite way to the tendency metioned above. The different sorption sites indicated by these kinetic studies can be divided into three types. ${ }^{9}$ (1) Sites on the planar surfaces; the sorption on kaolinite is probably mainly of this type and leads mostly to reversible
Table 3. Steady-state $R_{\mathrm{D}}$ values for the sorption of $\mathrm{Cs}^{+}, \mathrm{Sr}^{2+}$ and $\mathrm{Ba}^{2+}$ and the cation-exchange capacities of the clays

\begin{tabular}{|c|c|c|}
\hline \multirow[b]{2}{*}{ Clay } & $R_{\mathrm{D}} / \mathrm{ml} \mathrm{g}^{-1}$ & \multirow{2}{*}{$\begin{array}{c}\mathrm{CEC} / \text { mequiv. } \\
\text { per } 100 \mathrm{~g}^{\dagger}\end{array}$} \\
\hline & $\mathrm{Ba}^{2+} \mathrm{Sr}^{2+*} \mathrm{Cs}^{+*}$ & \\
\hline Kaolinite . & $\begin{array}{lll}127 & 135 & 1935\end{array}$ & 6 \\
\hline Montmorillonite & $\begin{array}{lll}238 & 1586 & 3607\end{array}$ & 21 \\
\hline Chlorite $\ldots$ & $745 \quad 126 \quad 1349 *$ & 15 \\
\hline
\end{tabular}

sorption. (2) Sites at the edges of the clay interlayers; these sites would not be accessible to cations of different size and charge. (3) Sites along the interlattice layers of collapsed or non-expanding clay minerals; the sorption of cations at these positions is mostly irreversible. The sorption of the $\mathrm{Ba}^{2+}$ ion on montmorillonite and chlorite appears to involve mainly sites of type (2) and (3).

\section{Conclusions}

Kaolinite, montmorillonite and chlorite type clays were found to sorb $\mathrm{Ba}^{2+}$ ions appreciably, with increasing $R_{\mathrm{D}}$ values in that order. Sorption on kaolinite was reversible, whereas that on montmorillonite and chlorite was only partially reversible. Hence from the point of view of environmental contamination, chlorite appears to be the most suitable sorbent for radiobarium.

The sorption isotherms were found to be linear with the Freundlich exponent close to unity. Langmuir type isotherm representation was found to be poor in providing a representation of the sorption of the $\mathrm{Ba}^{2+}$ ion.

The alkali metal $\mathrm{Cs}^{+}$is sorbed much more strongly than the alkaline-earth metal ions $\mathrm{Ba}^{2+}$ and $\mathrm{Sr}^{2+}$, whereas no significant difference was observed in the sorption behaviour of $\mathrm{Sr}^{2+}$ and $\mathrm{Ba}^{2+}$ ions on the three types of clay studied.

This work was supported, in part, by the International Atomic Energy Agency, Vienna, and by the Turkish Atomic Energy Authority, Ankara.

\section{References}

1. Erten, H. N., Aksoyoğlu, Ş., and Göktürk, H., Sci. Total Environ., 1988, 69, 269

2. Erten, H. N., Aksoyoğlu, Ş., Hatipoğlu, S., and Göktürk, H., Radiochim. Acta, 1988, 44/45, 147

3. Torstenfelt, B., Radiochim. Acta, 1986, 39, 97

4. Lieser, K. H., Gleitsmann, B., Peschke, S., and Steinkopff, Th., Radiochim. Acta, 1986, 40, 39.

5. Brauwer, E., Baeyens, B., Macs, A., and Cremers, A., $J$. Phys. Chem., 1983, 87, 1213.

6. Grütter, A., Von Gunten, H. R., and Rössler, E., Clays Clay Miner., 1986, 34, 677.

7. Co-ordinating Group on Geological Disposal of Radioactive Wastes, "Sorption, Modelling and Measurement for Nuclear Waste Disposal Studies," Report of the NEA Workshop, Paris, 6-7 June, 1983.

8. Searle, P. L., Aust. J. Soil. Res., 1986, 24, 193

9. Evans, D. W., Alberts, J. J., and Clark, R. A., Geochim. Cosmochim. Acta, 1983, 47, 1041.

Paper $8 / 02842 G$

Received July 14th, 1988 Accepted November 11th, 1988 